\title{
Effect of Chemical Composition on Structure and Properties of Ultrafine Grained Cu-Cr-Zr Alloys Produced by Equal-Channel Angular Pressing
}

\author{
Alexei Vinogradov ${ }^{1, * 1}$, Yasushi Suzuki ${ }^{2, * 2}$, Takahiko Ishida ${ }^{2, * 3}$, \\ Kazuo Kitagawa ${ }^{2}$ and Vladimir I. Kopylov ${ }^{3}$ \\ ${ }^{1}$ Department of Intelligent Materials Engineering, Osaka City University, Osaka 558-8585, Japan \\ ${ }^{2}$ Department of Mechanical Systems Engineering, Kanazawa University, Kanazawa 920-8667, Japan \\ ${ }^{3}$ Physical-Technical Institute of National Academy of Science of Belarus, Minsk 220141, Belarus
}

The properties of multi-functional $\mathrm{CuCr}$ and $\mathrm{CuCrZr}$ alloys with ultra fine grains (UFG) produced by equal-channel angular pressing (ECAP) have been investigated in dependence of concentration of alloying elements. A special attention is paid to optimization of fatigue performance together with strength, thermal and electric properties after ECAP and subsequent aging. Substantial improvement of fatigue life is evidenced in ECAP-fabricated alloys when compared with conventional tempers.

(Received January 20, 2004; Accepted March 3, 2004)

Keywords: copper alloys, severe cold working, aging, mechanical properties, fatigue

\section{Introduction}

Equal-channel angular pressing $(\mathrm{ECAP})^{1-3)}$ is a coldworking technique utilizing intensive simple shear for structure refinement and enhancement of physical and mechanical properties in a broad variety of materials. Many engineering applications require a rather sophisticated combination of materials characteristics. Copper alloys are widely used when a good electrical conductivity is required in combination with high tensile and cyclic strength and thermal stability. ${ }^{4}$ ) For example, it has been demonstrated recently that $\mathrm{CuCrZr}$ alloys can be effectively used in highspeed railways where progressing train speed imposes increasingly severe demands to the strength of the contact wire. ${ }^{5)}$ In the latter case it is particularly important to obtain a superb endurance limit in the high-cyclic fatigue (HCF) together with a good resistance to short time periodic overloads in the low-cyclic fatigue (LCF) regime. The requirement of having the electric conductivity exceeding at least $75 \%$ IACS (international annealed copper standard) limits the possibility of strengthening the materials for electro-mechanical applications by impurities which concentration should be kept as low as possible for satisfactory electric performance. At the same time, the ECAP technique seems to be most efficient for strengthening of less alloyed systems when the potential of Hall-Petch hardening can be fully realized while the solid solution and precipitation hardening can mask the effect of grain refinement. Therefore, as long as the complex multifunctional properties are of major concern, the material should be carefully designed to meet practical requirements. The effect of ECAP on enhancement of properties of $\mathrm{Cu}-0.44 \mathrm{Cr}-0.21 \mathrm{Zr}$ alloy has been discussed in detail ${ }^{6}$ ) and the significance of the number

\footnotetext{
${ }^{* 1}$ Corresponding author, E-mail: alexei@imat.eng.osaka-cu.ac.jp

${ }^{* 2}$ Graduate Student, Kanazawa University. Present address: Toyota Industries Corp., Kariya, Japan

${ }^{* 3}$ Graduate Student, Kanazawa University
}

of ECA-pressings as well as of the post-ECAP aging has been demonstrated for the remarkably improved mechanical properties. However, the role of chemical composition has not been explored so far. Therefore, in the present work we report on experimental findings concerning the multi-functional properties of $\mathrm{CuCrZr}$ alloys having different concentrations of components. Special attention is paid to the properties of main interest-tensile and fatigue strength, thermal stability and electric conductivity.

\section{Experimental Procedure}

The following chemical compositions have been chosen for the present study: $\mathrm{Cu}-0.36 \mathrm{Cr}, \mathrm{Cu}-0.44 \mathrm{Cr}-0.21 \mathrm{Zr}$ and $\mathrm{Cu}-$ $0.8 \mathrm{Cr}-0.05 \mathrm{Zr}$ (in mass\%). Before ECAP the billets of $14 \mathrm{~mm}$ $\times 15 \mathrm{~mm} \times 175 \mathrm{~mm}$ dimensions were solution treated at $1040^{\circ} \mathrm{C}$ for $30 \mathrm{~min}$ and quenched in a $5 \%$ water solution of $\mathrm{NaCl}$. Eight ECA-pressings have been performed through $90^{\circ}$ die-set with $0.4 \mathrm{~mm} / \mathrm{s}$ velocity at room temperature via the so-called "route Bc" when the sample was rotated through $90^{\circ}$ clockwise about working axis between subsequent passes.

The samples for mechanical testing were shaped by spark erosion to have a nearly square cross-section of $2 \times 2 \mathrm{~mm}^{2}$ and a gauge length of $10 \mathrm{~mm}$ and $3 \mathrm{~mm}$ for tensile and fatigue tests respectively. The specimen axis was aligned with the extrusion direction. All specimens were mechanically and electrolytically polished before testing. The LCF experiments were carried out on an Instron hydraulic frame under plastic strain control in fully-reversed tension-compression at constant plastic strain amplitudes, $\varepsilon_{\mathrm{pl}}=\Delta \varepsilon_{\mathrm{pl}} / 2$, ranged from $5 \times 10^{-4}$ to $1 \times 10^{-2}$ and at the average cyclic strain rate of $1 \times 10^{-2} \mathrm{~s}^{-1}$ in ambient air at room temperature. The constant stress amplitude was applied in the course of HCF tests. The tensile tests were performed on the same testing machine with a constant strain rate of $10^{-3} \mathrm{~s}^{-1}$.

To obtain maximum strength after ECAP and to satisfy the requirements of electric conductivity, the specimens were 
subjected to isothermal aging at different temperatures using the infra-red furnace allowing rapid heating and precise temperature control in vacuum. Differential scanning calorimetry (DSC, Rigaku 8230) helped to evaluate the thermal stability of ECAP structure and to monitor the phase transformations under linear heating with a constant heating rate of $20 \mathrm{~K} / \mathrm{min}$. The Vickers microhardness was measured on the plane perpendicular to the extrusion direction in the as fabricated ECAP state after different heat treatments. The applied load was $500 \mathrm{~g}$, and the loading time was of $15 \mathrm{~s}$. The average values of at least five successive measurements were calculated. The electric conductivity prior to and after annealing was measured relative to the IACS.

A $200 \mathrm{kV}$ transmission electron microscope JEOL 2000FX equipped with an energy dispersive X-ray spectrometer (EDS) was used to characterize the structure after ECAP and subsequent aging. The thin foils were prepared from the flow plane of the billet.

\section{Results}

\subsection{Structure}

The structure of $\mathrm{Cu}-0.44 \mathrm{Cr}-0.2 \mathrm{Zr}$ alloy after ECAP and subsequent aging has been reported in Ref. 6) in some details. Here let us illustrate the typical features of ultrafine structures for $\mathrm{CuCrZr}$ alloys by TEM micrographs for the $\mathrm{Cu}-0.8 \mathrm{Cr}$ $0.05 \mathrm{Zr}$ specimen, as shown in Fig. 1. The TEM photographs were taken from the billet's flow plane. One can see a rather uniform structure with nearly equiaxed grains of $200 \mathrm{~nm}$ size in average. The grain boundaries are significantly curved and contain numerous offsets. Many grain boundaries are not clearly visible because of a high dislocation density in their intimate vicinity. Although a large number of high-angle grain boundaries exist in the ECAP structure, the significant fraction of low-angle boundaries is also apparent. The extinction contours perpendicular to the grain boundaries indicate the presence of strong elastic stresses in the grain interior, which most likely have been produced by severely distorted grain boundaries. After aging the structure remain fine without appreciable grain coarsening, Figs. 1(c), (d). However, the grain boundaries become more clearly visible, i.e. some recovery occurred in the grain boundaries and their vicinity. The narrow annealing twins can be found in the fine structure after aging, Fig. 1(c). Cr-rich precipitates are visible along the grain boundaries primarily, Fig. 1(d), although the EDS analysis identifies precipitates in the grain bodies as well.

\subsection{Thermal stability, electric conductivity and aging conditions}

The importance of aging for deformation-processed $\mathrm{Cu}$ based alloys, including those fabricated by ECAP, has been well understood for optimization of properties of intereststrength and electrical conductivity. ${ }^{7)}$ The DSC measurements, Fig. 2, reveal a multistage character of structural transformations in $\mathrm{CuCrZr}$ alloys upon heating. The onset of
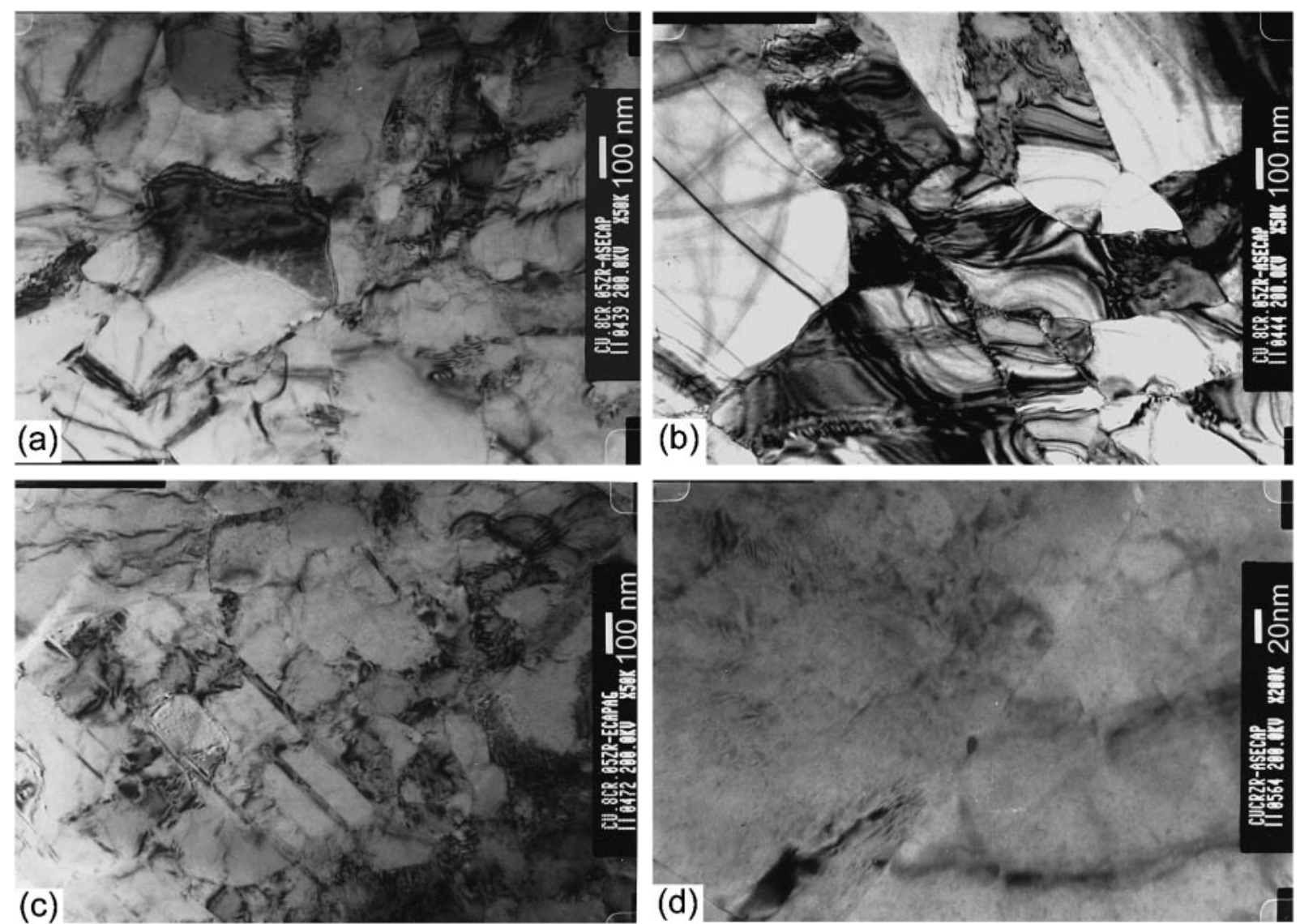

Fig. 1 Typical TEM micrographs showing the fine structure of $\mathrm{Cu}-0.8 \mathrm{Cr}-0.05 \mathrm{Zr}$ alloy after ECAP (a) and (b) and subsequent aging at $450^{\circ} \mathrm{C}$ for $1 \mathrm{~h}(\mathrm{c})$ and (d). 


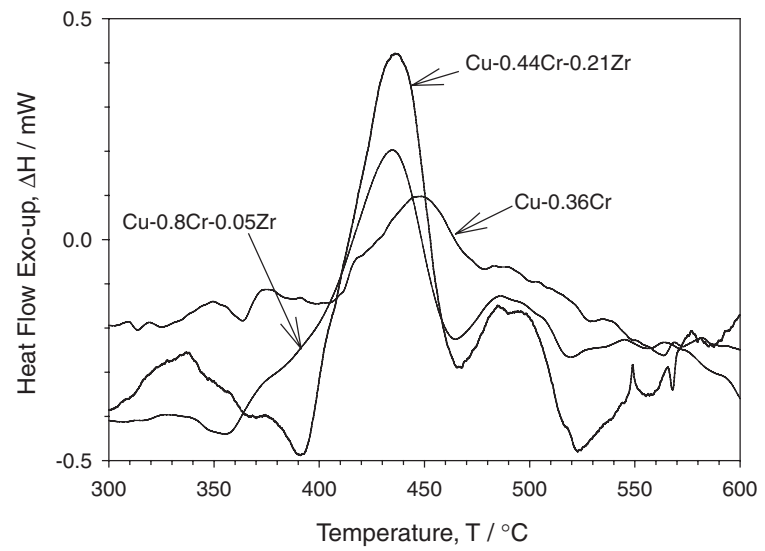

Fig. 2 The enthalpy release rate during linear heating of the ultrafine grain $\mathrm{Cu}-\mathrm{Cr}-\mathrm{Zr}$ alloys.

the first exothermal reaction in $\mathrm{Cu}-0.44 \mathrm{Cr}-0.2 \mathrm{Zr}$ is noticed about $220^{\circ} \mathrm{C}$ and the first DSC peak arises around $350^{\circ} \mathrm{C}$. The second strong maximum is achieved near $440^{\circ} \mathrm{C}$. A similar behavior is noticed in the $\mathrm{Cu}-0.8 \mathrm{Cr}-0.05 \mathrm{Zr}$ alloy. The precipitation kinetics in ternary alloys is more complex than that of binary ones; however, the peak around $440^{\circ} \mathrm{C}$, which is associated with $\mathrm{Cr}$ precipitation, appears most pronounced for all alloys investigated. These findings are in line with former detailed investigations of precipitation kinetics in binary $\mathrm{CuCr}, \mathrm{CuZr}$ and ternary $\mathrm{CuCrZr}$ alloys, ${ }^{8)}$ where it was found that in the as-quenched specimens $\mathrm{Cr}$ precipitates appeared first at about $440^{\circ} \mathrm{C}$ and then $\mathrm{Cu}_{3} \mathrm{Zr}$ precipitation occurred separately at about $520^{\circ} \mathrm{C}$. In the cold-worked specimens, the order of precipitation was reversed, that is, $\mathrm{Cu}_{3} \mathrm{Zr}$ and $\mathrm{Cr}$ appeared at about $370^{\circ} \mathrm{C}$ and $425^{\circ} \mathrm{C}$, respectively. Two precipitation temperatures observed in the ternary alloy agreed well with those of the respective binary alloys in the above cited paper. ${ }^{8)}$

The dependence of $\mathrm{H}_{V}$ on aging temperature is illustrated in Fig. 3(a) for all specimens. The temperature, at which the maximum $\mathrm{H}_{\mathrm{V}}$ magnitude is achieved, depends on the amount of impurities. Since we are interested in the highest achievable strength, the peak aging conditions, i.e. 375, 425 and $500^{\circ} \mathrm{C}$, were chosen for further testing of $\mathrm{Cu}-0.36 \mathrm{Cr}$, $\mathrm{Cu}-0.44 \mathrm{Cr}-0.2 \mathrm{Zr}$ and $\mathrm{Cu}-0.8 \mathrm{Cr}-0.05 \mathrm{Zr}$ alloys, respectively. At the same conditions, the satisfactory electric properties have been obtained as illustrated in Fig. 3(b) and Table 1. To meet the industrial needs, the $\mathrm{Cu}$-based alloys for electromechanical applications must possess the electric conductivity $\sigma_{\mathrm{el}}$ better than $75-80 \%$ IACS. ${ }^{5,9)}$ As shown in Fig. 3(b), the electric conductivity of as-fabricated ECAP samples is
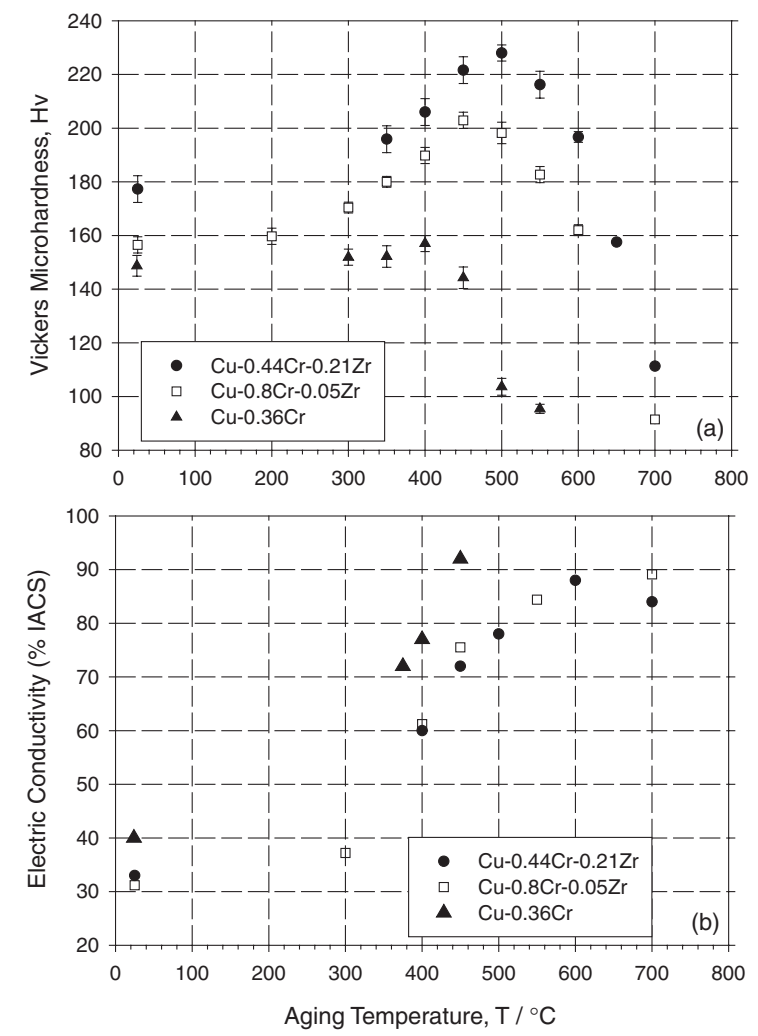

Fig. 3 Vickers microhardness $\mathrm{H}_{\mathrm{V}}$ (a) and electric conductivity (b) of ultrafine grain $\mathrm{Cu}-\mathrm{Cr}-\mathrm{Zr}$ alloys as a function of aging temperature (aging time is of $1 \mathrm{~h}$ ).

very poor, $\sigma_{\mathrm{el}}$ of $25-30 \% \mathrm{IACS}$, which is not acceptable. The post-ECAP peak aging improves this property up to affordable magnitudes. Vinogradov et al. ${ }^{6)}$ have demonstrated that grain growth in the ECAP $\mathrm{Cu}-0.44 \mathrm{Cr}-0.2 \mathrm{Zr}$ becomes appreciable at temperatures higher than $550{ }^{\circ} \mathrm{C}$, i.e. the former results as well as the present DCS data show that a good thermal stability is achieved in the UFG state of $\mathrm{Cu}$ based alloys subjected to severe plastic deformation.

\subsection{Mechanical behavior}

Tensile stress-strain curves for the peak aged samples are shown in Fig. 4. The results of mechanical testing of an ordinary commercial $\mathrm{Cu}-(0.9-1.3) \mathrm{Cr}$ alloy produced by Yamaha Corp. (Japan) are plotted for comparison. One can see that despite notably lower concentration of $\mathrm{Cr}$, the ECAP $\mathrm{Cu}-0.36 \mathrm{Cr}$ alloy reveals the same yield stress $\sigma_{\mathrm{y}} \approx 390 \pm$ $20 \mathrm{MPa}$ as the cold-drawn $\mathrm{Cu}-(0.9-1.3) \mathrm{Cr}$. It is not surprising that the ternary $\mathrm{Zr}$-containing alloys exhibit higher strength than the binary $\mathrm{CuCr}$ alloys. The highest strength of $710 \mathrm{MPa}$

Table 1 Properties of $\mathrm{Cu}-\mathrm{Cr}-\mathrm{Zr}$ alloys.

\begin{tabular}{|c|c|c|c|c|c|c|}
\hline & \multicolumn{2}{|c|}{$\mathrm{Cu}-0.31 \mathrm{Cr}-0.07 \mathrm{Zr}$} & \multirow{2}{*}{$\begin{array}{l}\mathrm{Cu}-(0.9-1.3) \mathrm{Cr} \\
\text { (Yamaha Corp) }\end{array}$} & \multicolumn{3}{|c|}{ ECAP followed by peak aging } \\
\hline & Wire $^{5)}$ & $\operatorname{Rod}^{5)}$ & & $\mathrm{Cu}-0.36 \mathrm{Cr}$ & $\mathrm{Cu}-0.8 \mathrm{Cr}-0.05 \mathrm{Zr}$ & $\mathrm{Cu}-0.44 \mathrm{Cr}-0.2 \mathrm{Zr}$ \\
\hline $\mathrm{H}_{\mathrm{V}}(\mathrm{MPa})$ & 160 & 170 & $150 \pm 14$ & $162 \pm 8$ & $202 \pm 5$ & $230 \pm 12$ \\
\hline$\sigma_{\text {UTS }}(\mathrm{MPa})$ & 609 & 555 & $460 \pm 5$ & $445 \pm 5$ & $595 \pm 5$ & $710 \pm 7$ \\
\hline$\delta(\%)$ & 6.2 & 6.2 & $19 \pm 2$ & $23 \pm 3$ & $14 \pm 2$ & $12 \pm 2$ \\
\hline$\sigma_{\mathrm{f}}(\mathrm{MPa})$ & - & 120 & 110 & $210 \pm 7$ & $240 \pm 6$ & $280 \pm 8$ \\
\hline
\end{tabular}




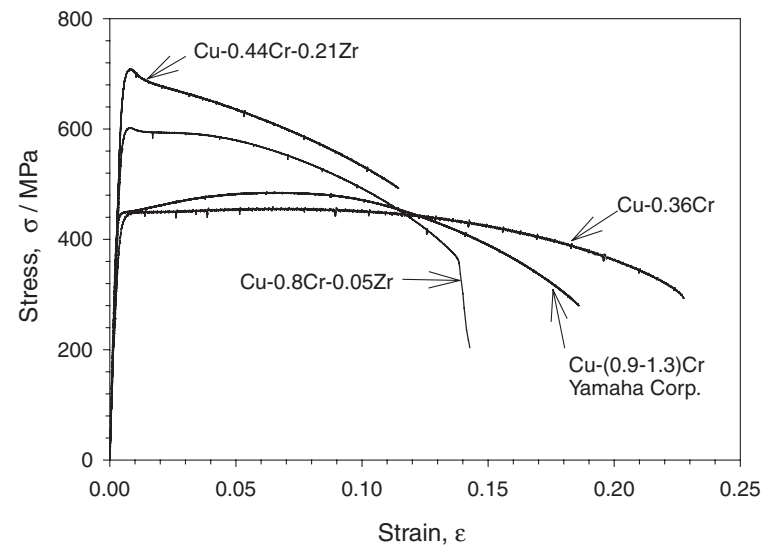

Fig. 4 Tensile stress-strain curves of the peak aged ECAP $\mathrm{Cu}-0.44 \mathrm{Cr}$ $0.21 \mathrm{Zr}, \mathrm{Cu}-0.8 \mathrm{Cr}-0.05 \mathrm{Zr}$ and $\mathrm{Cu}-0.36 \mathrm{Cr}$ alloys. The tensile stress-strain curve for the commercial $\mathrm{Cu}-\mathrm{Cr}$ alloy produced by Yamaha Corp. (Japan) is shown for comparison.

is reached in the $\mathrm{Cu}-0.44 \mathrm{Cr}-0.21 \mathrm{Zr}$ alloy which appears to be markedly higher than the results typically reported for commercially available $\mathrm{CuCrZr}$ alloys such as $\mathrm{C} 18150$ alloy $\left.\left(\mathrm{Cu}-1 \mathrm{Cr}-0.15 \mathrm{Zr}, \sigma_{\mathrm{UTS}}=425 \mathrm{MPa}\right)^{10}\right)$ (see also Table 1 for other examples). It is worth noticing that all UFG ECAPfabricated alloys reveal significantly higher ductility than their ordinarily produced counterparts. It turns out that the addition of $\mathrm{Zr}$ is particularly significant for the strength of UFG ECAP alloys: $\mathrm{Cu}-0.44 \mathrm{Cr}-0.21 \mathrm{Zr}$ possesses higher strength than $\mathrm{Cu}-0.8 \mathrm{Cr}-0.05 \mathrm{Zr}$ although the latter contains a greater total amount of solutes than the former.

As we have stated in Introduction, the HCF resistance of $\mathrm{Cu}$-based alloys can be a property of particular engineering interest. The results of HCF testing are shown in Fig. 5. One can see that ECAP CuCrZr does not have an apparent endurance limit in the range of number of cycles up to $10^{7}$.

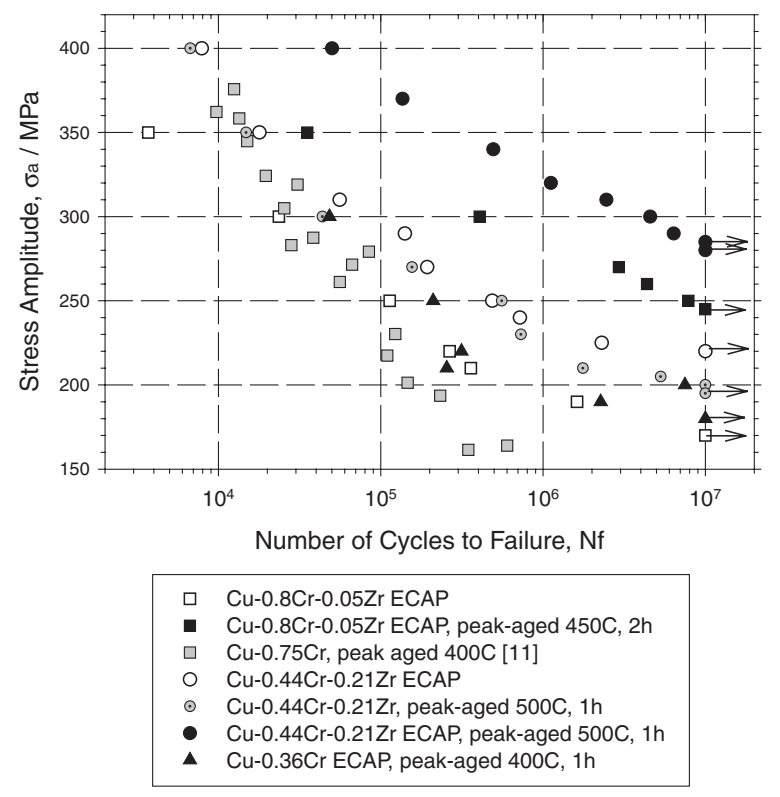

Fig. 5 Wöhler plots for ECAP $\mathrm{Cu}-\mathrm{Cr}-\mathrm{Zr}$ alloys in comparison with conventionally produced $\mathrm{Cu}$-based tempers.

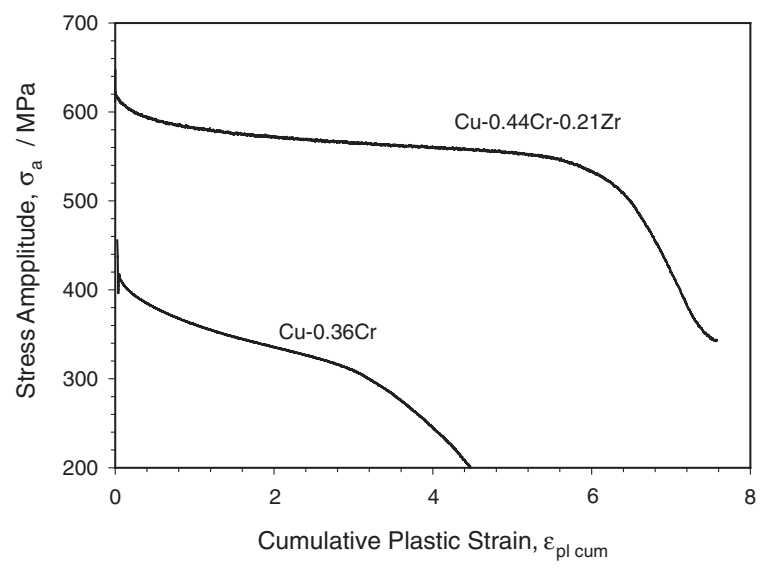

Fig. 6 Cyclic response of ECAP $\mathrm{Cu}-\mathrm{Cr}-\mathrm{Zr}$ alloys peak aged and tested under constant plastic strain amplitude $\Delta \varepsilon_{\mathrm{pl}} / 2=1 \times 10^{-3}$.

There is no any pronounced knee or trend to leveling on the $\mathrm{S}-\mathrm{N}$ (stress versus number of cycles to failure) curve. This is, however, typical of $\mathrm{Cu}$-based alloys. It is worth noticing that $\mathrm{HCF}$ life of ECAP CuCrZr is much longer than that of its conventionally produced counterparts. As can be seen in Fig. 6, the fatigue limit $\sigma_{\mathrm{f}}$ defined on the basis of $10^{7}$ cycles in ECAP Cu- $0.44 \mathrm{Cr}-0.2 \mathrm{Zr}$ is of $285 \mathrm{MPa}$ which is considerably higher than that for $\mathrm{Cu}-0.8 \mathrm{Cr}-0.07 \mathrm{Zr}\left(\sigma_{\mathrm{y}} \approx 100 \mathrm{MPa}, \sigma_{\mathrm{f}} \approx\right.$ $120 \mathrm{MPa}),{ }^{5} \mathrm{Cu}-1.98 \mathrm{Ni}-0.32 \mathrm{Be}$ beryllium bronze $\left(\sigma_{\mathrm{y}} \approx\right.$ $\left.700 \mathrm{MPa}, \sigma_{\mathrm{f}} \leq 250 \mathrm{MPa}\right)$ or binary $\mathrm{Cu}-0.75 \mathrm{Cr}\left(\sigma_{\mathrm{y}} \approx 310\right.$ $\left.\mathrm{MPa}, \sigma_{\mathrm{f}} \leq 100 \mathrm{MPa}\right) .{ }^{10-12)}$ Furthermore, Table 1 shows that the mechanical properties including fatigue limit of the ECAP CuCrZr alloys are remarkably higher than those of the cold-drawn peak aged $\mathrm{Cu}-0.31 \mathrm{Cr}-0.07 \mathrm{Zr}$ proposed in ${ }^{5)}$ as a potent candidate to be used as the contact wire for high-speed railways.

The cyclic response of all ECAP CuCrZr alloys is qualitatively similar as shown in Fig. 6. Intensive cyclic softening is observed in aged specimens. As has been demonstrated, cyclic softening in ECAP CuCrZr can be caused by dislocations cutting through fine precipitates. ${ }^{6)}$ Thus, cyclic softening should be dependent on the size, amount and distribution of precipitates. In line with these trivial expectations, Fig. 6 shows that the rate of softening differs for materials with different chemical compositions under the same testing conditions. Since the susceptibility to softening is very sensitive to the thermo-mechanical history of the specimens and, possibly, to the texture formed during processing, it seems plausible to suppose that cyclic softening is strain-path dependent. Detailed investigation of this issue is currently in progress and will be reported elsewhere. One can notice that the higher softening rate is observed in the peak-aged binary ECAP $\mathrm{Cu}-0.36 \mathrm{Cr}$ while the ternary $\mathrm{Cu}$ $0.44 \mathrm{Cr}-0.21 \mathrm{Zr}$ reveals slower softening and longer fatigue life despite somewhat lower tensile ductility of the latter alloy (see Table 1 and Fig. 4). It has long been recognized from the strain-based representation of fatigue life ${ }^{13)}$ that in the low-cyclic regime at fairly large strains, the plastic strain amplitude is dominant and fatigue life is controlled by ductility. However, it is apparent that the correlation between tensile ductility and crack propagation resistance associated with LCF properties is not straightforward particularly in 
dispersion hardened materials where the degradation of properties under LCF depends on a large number of factors including the particle size, distribution and the interaction of particles with moving dislocations. To the contrast, the HCF performance is governed by the elastic portion of the strain range, as would be logically expected from the correlation between the fatigue performance and yield properties or ultimate strength, Table 1 .

\section{Summary and Conclusions}

The ultrafine grain $\mathrm{CuCr}$ and $\mathrm{CuCrZr}$ dilute alloys with different concentrations of alloying elements have been fabricated by ECAP followed by heat treatment. The postECAP aging makes the precipitation hardened ultrafine grain structure rather stable under both thermal and mechanical influence. Optimal aging conditions are found to ensure the best high-cyclic fatigue performance in combination with good electric conductivity, strength and ductility. The significant improvement of tensile and HCF properties is observed together with improvement in ductility if compared to ordinary $\mathrm{CuCrZr}$ alloys fabricated by cold working and heat treatment. In combination with proven high thermal stability $^{6)}$ and good electric conductivity, the superior mechanical properties and fatigue resistance of ECAP $\mathrm{CuCrZr}$ open new perspectives for potential applications if the key obstacles associated with the production cost and scaling will be overcome. Both issues may find their resolution if, for example, the so-called CONFORM ("continuous forming") process ${ }^{14)}$ is realized industrially instead of multiple pressings of short billets. It seems clear that, the $\mathrm{Cu}$-based alloys with a broad diversity of properties can be manufactured by ECAP (or similar techniques involving severe plastic deformation) to meet industrial demands by varying chemical compositions, amount of strain and aging conditions.

\section{Acknowledgements}

The authors are indebted to Dr. M. Kawazoe (YKK Corporation, Japan) for his skilful help in TEM observations and to Mr. Y. Hayama and T. Yamazaki for experimental assistance.

\section{REFERENCES}

1) V. M. Segal: Mater. Sci. Eng. A 197 (1995) 157-164.

2) V. I. Kopylov: in Investigations and Applications of Severe Plastic Deformation, (eds.) Lowe, T. C. and Valiev, R. Z., NATO ASI Series 3, Kluwer, Netherlands, 80 (2000) 23-27.

3) R. Z. Valiev, R. K. Islamgaliev and I. V. Alexandrov: Progr. Mater. Sci. 45 (2000) 103-189.

4) A. A. F. Tavassoli: J. Nucl. Mater. 258-263 (1998) 85-96.

5) H. Nagasawa, S. Aoki, and A. Katayama: Quarterly Report of RTRI N3 (1998) 142-146.

6) A. Vinogradov, V. Patlan, Y. Suzuki, K. Kitagawa and V. I. Kopylov: Acta Mater. 50 (2002) 1636-1651.

7) T. W. Ellis, S. T. Kim and J. D. Verhoeven: J. Mater. Eng. Performance 4 (1995) 581-586.

8) H. Suzuki and M. Kanno: J. Japan Inst. Metals 36 (1972) 363-368 (Japan).

9) R. Sundberg and M. Sundberg: in Thermomechanical Processing in Theory, Modelling \& Practice, Proc. of Int. Conf. in Celebration of the 75th Anniversary of The Swedish Society for Materials Technology, Stockholm, Sweden, 4-6 Sept., 1996 (1996) 268-276.

10) ASM Specialty Handbook-Copper and Copper Alloys, (ed.) J. R. Davis, Davis \& Associates, (ASM International, Metals Park, OH, 2001) 600p.

11) A. A. Gadalla and V. Gerold: Indian J. Pure \& Appl. Phys. 18 (1980) 383-386.

12) K. D. Leedy, J. F. Stubbins, B. N. Singh and F. A. Garner: J. Nucl. Mater. 233-237A (1996) 547-552.

13) S. Suresh: Fatigue of Materials, Cambridge University Press, UK (1991) 617p

14) V. M. Segal, V. I. Reznikov, V. I. Kopylov, D. A. Pavlik and V. F. Malyshev: Processes of Plastic Structure Formation of Metals, Nauka i Tehnika, Minsk (1994) 232p. (in Russian). 